\title{
Patient "Demand" for Medical Interventions: Exerting Pressure for an Offer in a Primary Care Clinic Visit
}

\author{
Virginia Teas Gill \\ Department of Sociology \\ Illinois State University
}

\begin{abstract}
Contemporary medical decision making has been characterized as a struggle between patients who are reportedly making more demands for medical interventions such as diagnostic tests and prescription drugs and physicians who are encouraged to partner with patients and satisfy them while simultaneously keeping medical costs down. Understanding this dynamic requires attention to the interactional strategies whereby patients indicate what they desire, how physicians respond, and how the participants apply and react to pressure for particular outcomes. This investigation is a single case analysis of a primary care visit recorded in a general internal medicine outpatient clinic. Using conversation analysis, it reveals how a patient exerts subtle but persistent pressure for a diagnostic test and how the physician responds to her persuasive efforts.
\end{abstract}

Over the last 30 years in the United States, medical patients have been encouraged and empowered to take their medical care into their own hands - to become knowledgeable and informed about their own bodies, their diagnoses, and their treatments. People now have access to more health-related information than ever before through the Internet and

\footnotetext{
Early versions of this article were presented at meetings of the American Sociological Association (2003), the International Communication Association (2003), and at the International Conference on Conversation Analysis (2002). I thank Don Zimmerman and the anonymous ROLSI reviewers for their detailed comments. Thanks also to Doug Maynard and Maura Toro-Morn.

Correspondence should be sent to Virginia Teas Gill, Department of Sociology, Illinois State University, Normal, IL 61790. E-mail: vtgill@ilstu.edu
} 
through direct-to-consumer advertising of prescription drugs in print media and on television. Many of these advertisements entreat patients to "Ask your doctor about [name of medication]." As a result, patients are reportedly making more demands for medical interventions such as prescription drugs and diagnostic tests (Avorn \& Solomon, 2000; Bradley \& Zito, 1997; Lipsky \& Taylor, 1997; Peyrot, Alperstein, Van Doren, \& Poli, 1998; Weijer, Singer, Dickens, \& Workman, 1998).

Simultaneously, there has been a movement toward patient-centered medicine wherein physicians are encouraged to form partnerships with patients; invite their participation; and exhibit responsiveness to their desires, beliefs, and preferences. ${ }^{1}$ This movement has been driven, in part, by concerns about health care quality. Patients who actively participate in medical decision making may have better health outcomes than those who are passive (Greenfield, Kaplan, \& Ware, 1985; Greenfield, Kaplan, Ware, Yano, \& Frank, 1988; Kaplan, Greenfield, \& Ware, 1989). As Holman and Lorig (2000) argued, the effective management of the most prevalent diseases virtually requires patient-physician partnerships:

\footnotetext{
When acute disease was the primary cause of illness patients were generally inexperienced and passive recipients of medical care. Now that chronic disease has become the principal medical problem the patient must become a partner in the process, contributing at almost every decision or action level. This is not just because patients deserve to be partners in their own health care (which, of course, they do) but also because health care can be delivered more effectively and efficiently if patients are full partners in the process. (p. 526)
}

Many health insurers now base a portion of physicians' pay on patient satisfaction, which may provide physicians with a financial incentive to be responsive to patients' requests for medical services by giving them what they ask for. However, this potential incentive to satisfy patients is accompanied by imperatives to limit services because many insurers also base physicians' pay on their economic performance. Physicians are rewarded for keeping patients' medical expenses low, and they can do this by limiting prescription drugs, surgeries, hospital stays, and diagnostic tests (Berger, 1997; Kowalczyk, 2002). To some observers, these concurrent social trends have turned medical decision making into a "tug of war" between patients and physicians (Avorn \& Solomon, 2000, p. 129).

These developments have driven several lines of empirical research that have explored physicians' responsiveness to patients' expectations, de- 
sires, and requests for care. For example, some researchers in the areas of health communication and health services have examined how likely physicians are to meet patients' expectations and desires and how, in turn, such responsiveness affects outcomes such as patient satisfaction (e.g., Brody et al., 1989; Butler, Rollnick, Pill, Maggs-Rapport, \& Stott, 1998; Froehlich \& Welch, 1996; Joos, Hickam, \& Borders, 1993; Kravitz et al., 2002; Kravitz, Callahan, Azari, Antonius, \& Lewis, 1997; Kravitz, Cope, Bhrany, \& Leake, 1994; Like \& Zyzanski, 1987; Macfarlane, Holmes, Macfarlane, \& Britten, 1997; Mangione-Smith, McGlynn, Elliott, Krogstad, \& Brook, 1999; Uhlmann, Inui, Pecoraro, \& Carter, 1988). Using previsit and/or postvisit interviews or questionnaires, these researchers have asked patients what they expected to receive from their physicians during their medical visits; postvisit, they have asked patients or physicians whether these expectations were met or fulfilled, and they have measured patient satisfaction. ${ }^{2}$ Findings are mixed as to whether physicians typically meet patients' expectations. Some studies have found high levels of fulfillment, others have found lower levels, and still others have discovered that the likelihood of fulfillment depends on the type of expectation. All of these studies have revealed some association between fulfillment and satisfaction. However, several have found that satisfaction is more dependent on doctors meeting patients' expectations and desires for information, education, or support during the clinic visit (Brody et al., 1989; Butler et al., 1998; Froehlich \& Welch, 1996; Joos et al., 1993; Mangione-Smith et al., 1999) than meeting their expectations for interventions such as prescription drugs, tests, and examinations.

Given the evident link between fulfilling expectations and producing satisfied patients, and given the intriguing finding that meeting patients' expectations for support and information may be as-or even more-important than fulfilling their desires for medical interventions, physicians (especially in primary care) who may have a simultaneous stake in providing appropriate care, satisfying patients, and controlling access to medical services may well ask what it means, in practice, to "fulfill" a patient's expectation. One limitation of these survey-based studies is that they are "indirect" (Like \& Zyzanski, 1987, p. 356); they cannot tell us whether patients actually voice their expectations for care during office visits by making requests (Uhlman, Inui, \& Carter, 1984) or how they do so. Nor can they reveal the manner in which physicians respond to patients-for example, whether they explicitly grant or deny care - or reveal whether or how physicians and patients engage in negotiation and/or persuasive activities dur- 
ing clinic visits. Thus, the specific behaviors and interactional processes that influence patient satisfaction and other assessed outcomes also remain unclear.

Other researchers have chosen observational methods to study the fulfillment of patients' requests. In a subset of this literature, researchers have observed or recorded doctor-patient interactions and coded them for content, with the primary goals of (a) assessing the frequency of certain types of requesting and responding behaviors and (b) determining how they correlate with various demographic and outcome variables such as patient satisfaction (Cegala, McClure, Marinelli, \& Post, 2000; Eisenthal, Koopman, \& Lazare, 1983; Kravitz et al., 2003; Kravitz, Bell, \& Franz, 1999; Lazare, Eisenthal, \& Wasserman, 1975; Sleath, Svarstad, \& Roter, 1997). Although some of these studies have used coding strategies that only take account of explicit requests and responses, several have recognized that patients may make requests in subtle ways, that doctors may respond in ways other than granting or denying requests, and that patients and physicians may engage in negotiations about whether requests will be fulfilled (e.g., Cegala et al., 2000; Kravitz et al., 2003, 1999). The use of observational methods represents an important methodological advance in the study of patients' requests and request fulfillment because the researchers can directly observe/hear what the participants actually said during medical visits rather than relying on participants' self-reports (see Scott et al., 2001). However, coding these observations often involves extracting utterances from their sequential contexts - their placement within sequences of talk-and placing them in mutually exclusive categories. Thus, the researchers cannot take into account the fact that participants interpret utterances in light of their placement within conversation or that an utterance can perform more than one action.

For example, Kravitz et al. (1999) found in their data a "natural division between requests for information and requests for action" and coded the utterance "Do you think stress might be causing my chest pain?" (pp. 873-874) as a patient's request for information about a psychosocial problem. However, patients place such queries in particular locations in conversation so that doctors will be more likely to hear and interpret them in certain ways; likewise, doctors interpret such queries using the preceding talk as a resource for understanding what patients need or desire and for what it is relevant for them (doctors) to do next. As an action, such a query may be as diverse as a complaint, explanation, disagreement, solicitation of con- 
cern, or a hint for an offer of medical services, and it may be performing several of these actions simultaneously. As in everyday talk, after the doctor responds to the patient's query, he or she will likely receive some indication from the patient of whether his or her interpretation of the query was correct. Kravitz et al.'s (1999) coding strategy makes it difficult to interpret the correlations they found between particular physician behaviors and patient satisfaction such as their finding that unfulfilled requests for action were more likely to lead to patient dissatisfaction than were unfulfilled requests for information.

However, Kravitz et al. (1999), in particular, have also recognized that physicians and patients may discuss requests in ways that could be characterized as negotiations. Kravitz et al. (1999) coded a request-response exchange as a negotiation "when the physician's initial demurral was met by a counter-request or demand from the patient" (pp. 874-875). Using this definition, they found that patients negotiated a request in 22 out of 139 clinic visits and that the presence or absence of negotiation did not significantly influence patient satisfaction. This led Kravitz et al. (1999) to suggest that "the quality [italics added] of the negotiation process may be more important in influencing patient evaluations than the presence or absence of negotiation" (pp. 876). Indeed, as Lazare et al. (1975) recognized 30 years ago, the negotiation process is at the very core of the clinical experience: "It is the coming together, the interaction, the dialogue between the patient who is formulating what he thinks he needs and the clinician who is formulating what he thinks is clinically appropriate" (p. 554). Understanding this process requires close attention to the organization of the interactional resources patients use to indicate what they want in clinic visits and the resources doctors use to respond to these indications as well as how activities such as pressuring, resisting, and the like are accomplished.

Conversation analysis ${ }^{3}$ (CA) provides a way to access and analyze these processes and is a promising approach to understanding the dimensions of the alleged tug of war between physicians and patients. CA research emphasizes the importance of utterance sequencing and placement as a resource for performing social actions and for providing for particular interpretations on the part of coparticipants. Certainly, speakers may make explicit requests and recipients may grant or refuse requests in the next turn as in an adjacency pair sequence (Schegloff \& Sacks, 1973). However, participants also accomplish these types of activities in ways that emerge and become recognizable over expanded sequences of talk (Robinson, 2001; 
Schegloff, 1990). Recent CA research on physician-patient interaction shows that patients and physicians use complex and often subtle interactional resources to make requests, to exert pressure for particular outcomes, and to comply with — and resist—competing proposals. For example, Stivers, Mangione-Smith, Elliott, McDonald, and Heritage (2003) found in their study of pediatric visits that it is rare for parents to overtly request antibiotics for their children. Practices such as mentioning a candidate diagnosis (e.g., "ear infection") during the problem presentation or positioning an inquiry about antibiotics after a doctor's nonantibiotic recommendation can suggest the relevance of antibiotic treatment (Stivers, 2002a, 2002b; Stivers et al., 2003). Similarly, by reporting a prior conversation about an addictive prescription drug just after a doctor has extended an offer to be of service, a patient can raise the issue of a refill without requesting it outright (Robinson, 2001). By reporting during the history taking that one is a member of a group at risk for a disease but was never tested for it, a patient can suggest that a diagnostic test may be needed without actually requesting it outright; downplaying that at-risk status allows a physician to demur without refusing to provide the test (Gill, Halkowski, \& Roberts, 2001). A patient may exert pressure on a doctor to agree to a medical intervention — such as a prescription drug refill — by using an extreme-case formulation to underscore the severity of the medical condition(s) for which they are taking the drug (Robinson, 2001).

In this article, I mean to contribute to this growing CA literature on patients' practices for indicating their desires and exerting pressure for medical interventions in clinic visits and the practices doctors use to respond to such initiatives. In the analysis, I focus on a clinic visit in which a patient inquires about a diagnostic test and then applies increasing pressure on her doctor to offer it. The patient never requests the test and the doctor never grants or denies it, nor does she offer it in response to the patient's pressure. However, near the conclusion of the visit, the doctor does indicate that the test will be ordered.

\section{DATA AND METHOD}

This investigation is a single case analysis (Schegloff, 1987) of an outpatient clinic visit that was videotaped in a large, hospital-based, general internal medicine clinic located in the Midwestern United States. ${ }^{4}$ The data are part of a corpus of 15 visits recorded at this clinic. The patient is a 
61-year-old White woman. The doctor, who is the patient's primary care physician and is previously acquainted with the patient, is also a White woman. She is in approximately her late 30 s.

I draw on a body of existing empirical findings from CA to analyze an extended fragment of talk that occurred during this clinic visit, with a focus on the organization of this particular social event and the various interactional resources the participants use to accomplish their activities. The goal is to show how the participants bring particular resources to bear during the visit, but I do not argue that these resources are used in all clinic visits.

\section{ANALYSIS}

The patient $(\mathrm{Pt})$ is visiting the doctor $(\mathrm{Dr})$ for a second opinion on a proposed foot surgery. After discussing her foot and the surgery, the doctor asks the patient what else she would like to talk about. The patient mentions several things including the fact that she recently met with her psychiatrist who increased the dosage of her antidepressant medication and that she has been experiencing sudden "fits of temper" and pain in her head. In Extract 1 following, she also reports tenderness under her rib, which she speculatively attributes to "the gall bladder" and then "kidney" (see Gill, 1998; Gill \& Maynard, in press): 5

(1) [SMAC 9:01]

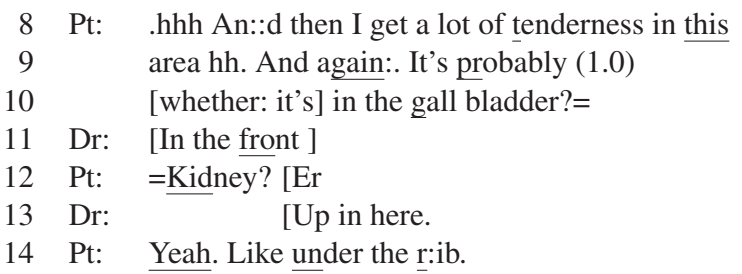

Then, in talk not reproduced here, the patient describes a sensation in her stomach that she describes as "A: sort of gla::.::agh (0.5) feeling." The doctor writes in the patient's chart and responds to each of the patient's symptom reports with queries and/or suggestions for managing the problem.

The patient looks down at a piece of paper she is holding and reports an additional symptom, tiredness (Extract 2a, line 2). She starts a speculative 
explanation for this symptom, "I don't know whether:," but then takes a more implicit approach and proposes a remedy: taking iron pills "again" to see if it "does anything" (lines 3 and 5). She thereby implies not only that anemia may be causing her fatigue but that she was diagnosed with and treated for anemia in the past and therefore that the condition has medical legitimacy:

(2a) [SMAC 10:35]

$\begin{array}{lll}1 & & (5.1) \\ & & (\text { doctor is writing in patient's chart) }) \\ 2 & \text { Pt: } & \begin{array}{l}\text { An:::d I've been very tired=h. (.) lately. I don't know } \\ \text { whether: I am tempted tah start taking iron pills again=hh }\end{array} \\ 3 & & \begin{array}{l}\text { (1.5) ((doctor nods while looking at patient's chart) }) \\ 4\end{array} \\ 5 & \text { Pt: } & \text { jus- (.) tuh see if it does: an(h)yth(h)i(h)ng .hhh } \\ 6 & & (1.2) \\ 7 & \text { Dr: } & \text { Lemme check your blood count [before you do] that } \\ 8 & \text { Pt: } & \text { [O:kay } \\ 9 & & \text { (.) }\end{array}$

Her doctor proposes checking a "blood count" before the patient takes such action (line 7), presumably to investigate whether the patient is anemic. The patient agrees (line 8). It is after this sequence and a micropause (line 9) that the patient questions the doctor about another diagnostic test. This is the focal extract, and it occurs approximately 10 minutes into the medical visit.

\section{Broaching the Diagnostic Test: Asking for Information}

In lines 10-11 (Extract 2b), the patient broaches the issue of an additional type of blood test called a SMAC. She does this by asking for information; specifically, she asks whether the clinic performs this test. The SMAC is a blood test that is also known as the Comprehensive Metabolic Panel. It is actually a group of several tests that provide information about the kidneys, liver, electrolyte and acid/base balance, blood sugar, and blood proteins. It is used as a screening tool to check for kidney disease, liver disease, and diabetes as well as to monitor problems such as hypertension:

(2b) [SMAC 10:51]

7 Dr: Lemme check your blood count [before you do] that

8 Pt: [O:kay ]

9 (.) 
10 Pt: An= $>\uparrow$ also $<$ do you-? do they do: $u$ uh $>$ what is it $-<$ (.)

11 uh Doctor Winoker called it thuh sma:c,

$12 \quad(0.3)$

13 Pt: Es em ay see

14 Dr: .hh $\uparrow$ A lotta times we do: n' if somebody is having

15 a lot of extra: fati:gue (0.3) I do

As the patient asks this question, the doctor is paging back through the patient's chart, reviewing her medical history. ${ }^{6}$ She does not immediately respond. In line 13, the patient pursues a response by clarifying the SMAC reference (Pomerantz, 1984c); she spells out the name of the test, "Es em ay see." This provides an account for why the doctor did not respond (that she did not understand the SMAC reference). The patient's pursuit also indicates that an answer to the question is conditionally relevant (Pomerantz, 1984c; Schegloff \& Sacks, 1973).

The patient's inquiry is designed as a yes-no interrogative that prefers a yes response (Raymond, 2003). A yes would inform the patient that the test is available, which will also let the patient know that the doctor is familiar with the test. This could establish the grounds for further questioning about the test and what the test is for, for the patient's own knowledge or for some other purpose. There are many reasons a patient could ask such a question, and at this point in the conversation, the patient does not explicitly indicate why she is inquiring about the availability of the test. There is some evidence, however, that the inquiry is a prerequest, a type of presequence that, contingent on the recipient's response, can eventuate in the speaker making a request — such as a request for something the speaker inquired about (Schegloff, 1988, 1990, 1995; Sacks, 1967/1992a). In the following example from everyday conversation (Schegloff, 1995, p. 88), Abby does a prerequest in the form of an inquiry. She asks Beth whether she has a copy of a book called The Cross and the Switchblade:

(from Schegloff, 1995, p. 88; labels added)

$\begin{array}{ll}\text { PREREQUEST } & \rightarrow 1 \text { Abby: And uhm I want(ed)to ask too, do you still have } \\ & \\ \text { GO-AHEAD } & \rightarrow 3 \text { Beth: Yeah. } \\ \text { REQUEST } & \rightarrow 4 \text { Abby: May I read it again? }\end{array}$

On receiving Beth's affirmative, go-ahead response (Schegloff, 1990, 1995), which indicates that she does have the book, Abby makes a request to read it. 
Several features of the patient's inquiry suggest that it is a possible prerequest. First, the patient places the inquiry immediately subsequent to the doctor's proposal to "check" her blood count, and she links it to that proposal with "An $=>\uparrow$ also $<$ " (Extract $2 b$, line 10). This provides for the inquiry to be heard not only as next in a series of concerns that require the doctor's help (Heritage \& Sorjonen, 1994) but also as relevant to the performance of an additional blood test. Second, the patient asks for information about whether the clinic does the test, not for general information about the SMAC test (e.g., what the test is, or what it is for). This suggests that she is working to establish whether the test is available to be performed. Additionally, the patient initially constructs her inquiry so that she is asking whether the doctor does the test, but then she repairs the referent, switching to the third person ("An= $>$ also $<$ do you-? do they do:"; line 10). That is, she asks whether the clinic performs the test. This subtle shift attends to the possibility that the doctor will hear the patient's inquiry as an indication that she desires the test and that the doctor could refuse to order it. Sacks (1967/1992a) noted that such sequences are regularly "collapsed"; so in response to inquiries that are possible presequence questions, "one will regularly get an answer that is directed to the sequence of which the question is seen to be a part" (p. 688). For example, in the following extract, a speaker inquires about whether a recipient has the ability to "fix this needle," and the recipient responds as if the speaker made a request to fix it; he declines, via the report "I' $m$ busy":

(from Sacks, 1967/1992a, p. 689)

Q: Can you fix this needle?

A: I'm busy

In lines 10-11 (Extract 2b), the patient appears to be orienting to the possibility of such a collapsed sequence. Specifically, by allowing the doctor to respond on behalf of the clinic, she provides the doctor with a candidate account for a refusal should the doctor hear the patient to be requesting the test and should she feel the test is unwarranted. The doctor can decline because the clinic does not do the test, a less disaffiliative response than refusing of her own volition or on her own behalf.

In other ways, the patient retains an equivocal position in regard to her activities. Although she evidently has some prior knowledge of the test from a prior medical context, it is downplayed with the word search in Ex- 
tract $2 b$, line 10 ("uh $>$ what is it-<(.)"); then, when she does produce the name of the test, she attributes knowledge of it to a third party, her former doctor: "Doctor Winoker called it thuh sma:c," (see Pomerantz, 1984b). ${ }^{7}$ Thus, she provides a justification for seeking more knowledge about the test and provides a rationale for the doctor to provide information in response to the inquiry. When patients use medical terminology, they generally do not "come right out" with the terms but rather display hesitancy and defer to doctors as the legitimate sources of the terminology (Drew, 1991, p. 38).

Should the patient desire the test, inquiring about its availability is a cautious approach. It addresses some potential problems attendant on requesting a diagnostic test outright including challenging the doctor's medical expertise and her authority to determine appropriate diagnostic tests (see Stivers, 2002a). An outright request would also make a granting or refusal the relevant next action for the doctor (Schegloff, 1995). In this phase of the medical interview, before the doctor has fully assessed the patient's history and physical condition, it may be premature (and thus unlikely) for the doctor to grant such a diagnostic test. In addition, for patients to request diagnostic tests "presupposes some determination of a candidate health problem or some level of risk for a problem" (Gill et al., 2001, p. 57). This patient is symptomatic (she has abdominal symptoms, pains in her head, and tiredness). By requesting a diagnostic test, the patient could be suggesting that she may have one of the diseases or conditions that the test is designed to diagnose such as kidney or liver disease. The patient exhibits a degree of caution that is characteristic when patients raise candidate explanations for illness (Gill, 1998; Gill \& Maynard, in press).

So, inquiring about the test allows the patient to be equivocal about her project. By making such an inquiry, the patient may be able to gauge what the doctor's likely response would be-because the doctor's response could reveal her orientation toward a pending request-without committing herself to having made an actual request (Sacks, 1967/1992a). Whether the patient eventually makes a request for the SMAC test may be contingent on the doctor's response.

At lines 14-15 (Extract 2b), the doctor responds affirmatively, indicating that the test is available. There is evidence that this turn is a possible go-ahead response, which would forward the sequence to a request (Schegloff, 1990, 1995). The doctor responds affirmatively, indicating that the test is not only available but would be available to this patient. She claims that the SMAC test is one the clinic does frequently ("^A lotta times we do:," 
line 14); apparently, the test is not reserved for rare or unusual circumstances. Additionally, she reports her own typical use of the test: She personally performs it if a patient is experiencing "extra fatigue" (lines 14-15). Fatigue is a symptom that the patient, just moments before, claimed to be experiencing (Extract 2a, line 2). By naming this particular precondition for the test, the doctor provides a strong indication that the test is not only available generally but would be available to and appropriate for this patient. Finally, her nonvocal behavior displays receptivity. Her gaze had been directed solely at the patient's medical chart for 35 seconds preceding this point in the conversation, and she had been writing in the chart and flipping back through its pages. At line 14 (Extract 2b), she puts the chart pages down over her left thumb, keeping her thumb in the chart seemingly to mark her place. Then at "I do" (line 15), she looks at the patient and nods affirmatively. The doctor thus marks a temporary break with her ongoing activities (reviewing the patient's medical history and making notes in the chart), and she takes on a posture that at least momentarily appears more receptive to further engagement on this matter. In several ways, then, her response indicates she would be receptive to a request for the SMAC test should the patient produce one.

The doctor's response does not entirely facilitate the move toward a request, however. It is a non-type-conforming response to a yes-no interrogative (Raymond, 2003, p. 946) in that it does not contain a form of yes or no (such as "Mm hmm," "yep," etc.). Thus, it does not fully conform to the constraints imposed by the patient's question. Although it does not frustrate or "block" (Schegloff, 1990, 1995) a move toward a request, it treats the patient's question - and the activity of delivering a yes or no in response-as somewhat problematic.

\section{Citing a Precedent for the Test}

The patient now has evidence that the doctor is familiar with the SMAC test and that she could potentially provide additional information about it or potentially offer it. Given the doctor's response, the sequence is forwarded so that patient has the opportunity to gather additional information should she desire it or request the test should that be her aim (Schegloff, 1995). The patient takes a different route: She begins to exert pressure on the doctor to offer the test by citing a precedent for offering it 
(Heritage, Boyd, \& Kleinman, 2001; Stivers, 2002a). In line 16 (Extract 2c following), the patient begins an account for having asked about the test ("Mkay cuz that-") and then cuts herself off and refers to her former doctor's stance (".hh he seemed t've-"), abandons this tack, and finally describes the former doctor's reaction to her health concerns: "whenever" she was "getting worried about- (0.3) soreness er lumps er stuff::," he regarded the SMAC test as "inclusive" (lines 16-18). Thus, the patient cites a precedent for offering the test by describing the positive stance that another medical professional took in regard to it when the patient was worried about her symptoms.

(2c) [SMAC 11:01]

14 Dr: .hh $\uparrow$ A lotta times we do: n' if somebody is having

15 a lot of extra: fati:gue (0.3) I do

16 Pt: Mkay cuz that- hh he seemed t've- whenever I wuz::

17 getting worried about- (0.3) soreness er lumps er stuff::

18 (0.3) he: seemed ta feel that that=was: an inclusive,

19 Dr: Mm hm?

$20 \quad$ (.)

21 Pt: [(one) ]

22 Dr: [.h TLK=What] it does is it- hh it checks a lot of

23 uh: blood tests from your- uh liver (on) your kidneys

24 an .hh uhm: your (b-) uh: the minerals an the salts in

25 your blood hh so it gives us $\mathrm{uh}_{-}>\mathrm{kind}=\mathrm{of}=\mathrm{uh}<\mathrm{uh}$

26 general scree:n [for:: ]

27 Pt: $\quad[\mathrm{Mm} h m$ ? $]$

28 Dr: whether th- $\mathrm{u}$ - a liver problem could be causing this. ((doctor gestures under her own lower right rib))

29 Dr: ${ }^{\circ}$ An those kinds of things, ${ }^{\circ}=$

30 Pt: =Mkay.

Note that when the patient reinvokes the former doctor's stance in regard to the test ("he: seemed ta feel that that=was: an inclusive ... (one)"), it is positioned as his response to her anxiety. There are locations in medical interviews, such as in problem presentation sequences, where patients typically normalize their symptoms rather than displaying such anxiety or concerns about them (Halkowski, in press). These displays serve as resources with which patients present themselves as reasonable patients who are attentive to their symptoms but not overly concerned about them (Halkowski, in press). However, in the present location, the patient's invocation of her re- 
current concerns about "soreness er lumps er stuff" provides a resource: It is an accountable way to report her former doctor's proactive response to her health concerns. ${ }^{8}$

The patient's account provides some new evidence that her initial inquiry (at lines 10-11, Extract 2b) was to be heard as an indication that she desired the test. However, if the doctor's response to the patient's inquiry was generally a go-ahead response, why didn't the patient go ahead and produce a request? The patient appears to be treating the doctor as somewhat resistant to her inquiry. She may be responding to the somewhat less than facilitative, non-type-conforming design of the doctor's response. More generally, however, the patient appears to be bidding for a different type of response than a go-ahead, a preemptive offer (Schegloff, 1990, 1995; see also Lerner, 1996; Sacks, 1967/1992a). As Schegloff (1995) argued, "the preferred response to the pre-request is to preempt the need for a request altogether by offering that which is to be requested"9 (p. 86). An example of a preemptive offer is as follows:

(from Sacks, 1967/1992a, p. 691; labels added)

$\begin{array}{ll}\text { PREREQUEST } & \rightarrow \text { A: What are those, cigars? } \\ \text { OFFER } & \rightarrow \text { B: Yeah. You want one? } \\ & \text { A: Sure }\end{array}$

If a recipient makes an offer in response to a prerequest, then the speaker need not make a request him or herself and face the risk that it will be rejected (Schegloff, 1990, 1995). It is possible, however, that the patient's initial inquiry did not provide the doctor with sufficient resources to recognize it as a prerequest and to respond with a preemptive offer. As Schegloff (1995) noted,

To be sure, it is not always possible for the projected request-recipient to anticipate what the request-target is to be, and it is not always projectable that it is a request which is in the offing. And projected request-recipients thus may have as a possible claim that they had not discerned the imminence of the request or its object. (p. 86)

Whether or not this is the case, by producing an account for why she asked and by citing a precedent for the test, the patient behaves as if an offer was the relevant response to her inquiry. Her account reforwards the sequential 
implications of that inquiry, giving the doctor another opportunity to respond with an offer.

Much of the ensuing talk can be characterized as a negotiation over whether the doctor will offer the test to the patient or whether the patient will produce a request on her own. At the beginning of the patient's account (line 16, Extract 2c), the doctor reengaged in activities related to reviewing the patient's medical history. At the end of line 17, she flips up a page in the medical chart with her left hand and nods, looking at the page she is holding up. She acknowledges the patient's account with "Mm $\mathrm{hm}$ ?" on its projected completion (line 19) and then assumes a more receptive posture: She puts down the chart page that she has been holding up (again keeping her left thumb under the page, indicating that her orientation to the patient is temporary), puts her right (writing) arm down on the desk so that is on top of her left hand, and looks at the patient. She provides more information about the test (lines 22-26, 28-29). This treats the patient's prior turn as a pursuit of more detailed information than the former doctor had provided. She first describes what the test "does": "it checks a lot of uh: blood tests from your- uh liver (on) your kidneys an .hh uhm: your (b-) uh: the minerals an the salts in your blood" (lines 22-25). She then describes the test as a "general screen" (line 26), a description that is aligned with the patient's characterization of her former doctor's position ("he: seemed ta feel that that=was: an inclusive ... (one)," lines 18 and 21). When describing what the test screens for, the doctor references one of the patient's own symptoms ("it gives us uh > kind=of=uh< uh general scree:n [for:: ] ... whether th- u- a liver problem could be causing this.") while gesturing under her rib in the location the patient had previously indicated was sore (see Extract 1). She implies that such an investigation might be useful for this patient because it could reveal whether a "liver problem" could be responsible for this symptom and others ("o An those kinds of things,, ," line 29). Given this portrayal of the test, it is possible that the doctor has already decided to order it for the patient. However, she does not indicate whether this is the case. Her use of the present tense ("it gives us uh $>$ kind=of=uh< uh general scree:n," lines 25-26) does not forecast any future actions in regard to the test.

\section{Praising a Predecessor}

The patient responds by exerting more pressure for an offer. In Extract $2 \mathrm{~d}$ (following), she acknowledges the doctor's turn with "Mkay" and then 
projects a description of her own reaction or response, presumably to having received the SMAC test in the past: "(That- that-) $>\mathrm{Cuz}$ it- $<$ it $\uparrow$ seemed tuh make me:" (line 32). This is built as another account for having inquired about the test (note the parallel in turn design to Extract 2c, line 16: "Mkay cuz that- .hh he seemed t've-") and as such, it again reforwards the implications of the patient's prerequest. After considerable disfluency where she starts and abandons several other approaches, the patient praises her former doctors' behavior: "I have:- had very:- (.) good doctors as far as: ... explaining: to me what my pr(h)ob(h)l(h)ems are" (Extract $2 \mathrm{~d}$, lines 34-35). Meanwhile, the doctor immediately orients back to the patient's chart (at the end of line 29). She looks at the top page and then flips up and examines the page that her left thumb has been holding. She then puts the page back down and writes in the chart while the patient praises her former doctors:

(2d) [SMAC 11:33]

29 Dr: ${ }^{\circ}$ An those kinds of things, ${ }^{\circ}=$

30 Pt: =Mkay.

31 Dr: $\quad[$.hhh

32 Pt: [(That- that- $)>$ Cuz it- $<$ it $\uparrow$ seemed tuh make me: (.)

33 An again. (.) cuz: (0.6) ah:m= (.) >I mus- I mean<

34 he was:: I have:- had very:- (.) good doctors as far as:

35 (2.5) explaining: to me what my $\operatorname{pr}(\mathrm{h}) \mathrm{ob}(\mathrm{h}) \mathrm{l}(\mathrm{h}) \mathrm{ems}$ are.=

36 Dr: $=[\uparrow \mathrm{Mm} \mathrm{hm}$ ?]

37 Pt: [.hh ]

38 Pt: An:d=uh=h I had gotten:- (0.5) I always felt tht after

39 he did that if he said everything was fine it wa:s.

40 Pt: .hh- (.) An I didn't get nervous about it. hh

$41 \quad(0.2)$

42 Pt: At least for another six months. $\mathrm{HH}$

43 Dr: Hih $^{\circ} \mathrm{ka}(\mathrm{h}) \mathrm{y} .{ }^{\circ}$

$44 \quad(\mathrm{Pt}):$.hhh

45 Pt: It's: ah=h (0.6) >I don't know.<

$46 \quad(0.8)$

47 Pt: Our minds're th- (.) our biggest problems.

$48 \quad$ (7.4)

49 Dr: So the $\uparrow$ medicines that you're on no:w, are thee

50 amitriptyle:ne,

Giving compliments and praise to one person can implicate others in complex ways. For example, praising a person who is not present can work to criticize a copresent participant who is in the same membership category 
(Sacks, 1971/1992b). "Praising a predecessor" (Maynard, 1998, p. 390) is one form this phenomenon can take. ${ }^{10}$ By praising the behavior of her former doctors at this juncture, the patient can be heard to assert a preference for how the copresent doctor should behave. The praise, then, is built not just as a reporting of her preferences for how doctors should behave but as a potential criticism of her current doctor for failing to offer an investigation into her symptoms to find out what is causing them. ${ }^{11}$ Notice the considerable disfluency in lines 32-35, which in delaying the production of the praise treats it as a sensitive matter and as a dispreferred activity (Pomerantz, 1984a). The patient's embedded laughter at line 35 ("pr(h)ob(h)l(h)ems") also marks her activity as "delicate interactional business" (Haakana, 2001, p. 212).

The doctor offers a continuer ("^ Mm hm?") and nods (line 36). She is still looking at the patient's chart, and at this point, she looks left to the page that is attached to the inside top cover of the patient's chart then back to the top page. At line 38, the patient retrieves the activity she had projected at line 32 and reports her reaction when her doctor ordered the SMAC test: The test allayed her nervousness ("I always felt tht after he did that if he said everything was fine it wa:s. .hh- (.) An I didn't get nervous about it. hh"). Note that in this retrieval, she also reformulates her reaction to the test, claiming "I always felt tht" (line 38), whereas her projected reaction in line 32 was $>$ Cuz it-< it $\uparrow$ seemed tuh make me:." This reformulation upgrades the extent of the relief she experienced on receiving the SMAC test; "always" also underscores that she had received the test more than once (perhaps routinely) in the past. This utterance exerts more pressure on the doctor to respond with an offer because it (a) establishes a behavioral precedent for the doctor to follow and (b) alludes to a negative consequence if she does not follow this precedent. Recall that when the patient first cited a precedent (Extract 2c, lines 16-18), she reported her former doctor's stance in regard to the test (he regarded it as "inclusive"). In lines 38-39 (Extract 2d), the patient upgrades that precedent, indicating via "after he did that" that the doctor had actually ordered the SMAC test.

Note also how the patient characterizes her reaction to having received the test. She claims it reassured her ("I always felt tht after he did that if he said everything was fine it wa: :s.," lines 38-39), and following this, she reports the absence of a negative reaction: It prevented or held off a negative consequence (“An I didn't get nervous about it. hh," line 40). Thus, she not only provides the copresent doctor with a model for behavior, she also provides a justification for performing the test in that historically, it has pro- 
vided reassurance and has prevented her from experiencing future anxiety. She reveals what is at stake in the current visit-she is worried and anxious about her health - and what it will take to appease her. She also underscores the degree of reassurance she requires by suggesting that it is not enough for a doctor to assert that "everything is fine"; rather, evidence from a diagnostic test is necessary to confirm this.

Although there is no way of knowing whether this patient did experience the anxiety she reports, other parts of the conversation provide evidence that the patient may have had a serious health problem in the past. During the visit, the doctor sought confirmation that the patient was having regular bone scans, which can be used to monitor the spread of some types of cancer as well as other conditions. The patient may be justified in feeling concerned about new or unusual symptoms. However, the central point here is that the patient mobilizes a display of anxiety, by confessing to it at a critical juncture in the medical visit and showing how her former doctor dealt with it, to solicit an offer for the SMAC test. She portrays the test as a tried-and-true remedy for her anxiety, and she offers her doctor both a candidate response (provide it like her former doctor did) and a negative consequence for failing to respond in this way (she implies that she will be worried and anxious no matter what the doctor says to reassure her).

After a brief silence at a transition-relevant place (line 41) where it is again relevant for the doctor to make an offer, the patient exerts still more pressure by upping the ante: She underscores the persistent, recurrent nature of her anxiety by claiming that after having the test, she did not get nervous "At least for another six months. HH" (Extract 2d, line 42). This is accompanied by a laughter token ("HH") and a smile, which treat it as a delicate move (Haakana, 2001). The doctor is still looking at the patient's chart at this point; at "six months" (line 42), she again begins paging back through the patient's chart and acknowledges the patient's turn with a smile and "Hih ${ }^{\circ} \mathrm{ka}(\mathrm{h}) \mathrm{y}$. "“" (line 43).

At line 45, the patient moves to close the topic. She changes her body position, reaching down toward her right foot and buckling one of her sandals (which had been taken off earlier when the doctor looked at her feet during their conversation about the foot surgery), simultaneously producing a figurative expression: "It's: ah=h $(0.6)>$ I don't know.< $(0.8)$ Our minds're th- (.) our biggest problems." (lines 45-47). Speakers regularly use these types of expressions to initiate topic closings (Drew \& Holt, 1998). However, with this utterance, the patient also backs down somewhat by admitting to excessive, possibly unjustified, anxiety—the "mind" (i.e., 
concern about potential health problems) may be worse than the actual physical problems people experience. She softens the personal implications of this statement by attributing it to patients in general, using the first-person, plural, possessive form "our" and then reinforcing this attribution by replacing a projected "the" with another "our" ("Our minds're th(.) our biggest problems.," line 47). Thus, although she may be capitulating, she also suggests that she is not unique and that other patients share her level of nervousness.

After a 7.4-second silence (line 48) in which the doctor is looking at prior pages in the patient's medical chart, the doctor begins a new sequence by stating, for the patient's confirmation, the medications she is taking (lines 49-50). They continue with the medical history.

\section{Indicating That the Test Will Be Ordered}

Despite the doctor's apparent openness to the SMAC test, having been given several sequential opportunities to offer the test, and the patient's persuasive efforts to procure an offer, the doctor has not offered the test nor indicated in another way whether she will order it. Several minutes later, during the physical exam, the patient inquires whether she can get "a printout on thee blood ... results stuff," offering as an account "cuz it's- it's better for my memory." Given that the doctor said earlier that she was going to perform a blood count (see Extract 2a), the doctor's response to this inquiry could potentially provide the patient with some indication of whether the doctor is also going to perform the SMAC test. The doctor immediately consents to providing such a printout but does not indicate which tests she will be performing. After the physical exam (when the video camera was turned off and only audio was available), the doctor indicates that she will, in fact, be ordering the SMAC test. Listing off the different tests she will order, the doctor includes the SMAC on the list of the things she is "gonna check" (Extract 3):

(3) [SMAC 23:15]

$\begin{array}{lll}1 & & (5.2) \\ 2 & \text { Dr: } & \text { I'm gonna check yer: thyroid=uh function make sure } \\ 3 & & \text { you're getting adequate thyroid replacement, } \\ 4 & \text { Dr: } & \text {.hh this: thing called a sma:c that we [talked ]about,= } \\ 5 & \text { Pt: } & \text { [Mka:y.] }\end{array}$


6 Dr: =and the blood counts?

7 Dr: An I will make sure that you get a copy of

8 Pt: Okay=

9 Dr: =the results.

By identifying the SMAC test as something "we talked about," the doctor ties the test to their prior conversation but she does not agree to provide the test in response to a "request." Her gloss of the conversation diminishes the patient's agency in having raised the matter and having exerted pressure to procure an offer. Although the patient will indeed receive the test, the doctor renders opaque the means by which this came about.

\section{DISCUSSION}

In this era of relatively well-informed patients and various (and at times conflicting) imperatives for physicians, it is important to understand how patients advocate for their own health care and how physicians respond. This article contributes to a growing body of conversation analytic research that is addressing the need for a more detailed exploration of these interactional processes. It reveals that patients and doctors have complex resources for making and responding to such initiatives.

In this single case analysis, I show how a patient uses an inquiry about the availability of a diagnostic test to broach the test in a way that suggests her interest in obtaining it but does not commit to a desire or an expectation. By providing the requested information, the doctor puts the ball back in the patient's court in terms of taking the initiative to request the test should she desire it. The patient does not request the test. She goes on to exert increasing pressure on the doctor to make an offer by citing a precedent for the test, praising the doctor's predecessors, and then reporting the positive effects of the predecessors' actions on her emotional state. Although the doctor exhibits some responsiveness to the patient by providing information about the test and what it does, she does not respond to the pressure by providing an offer. She makes it clear that her responses to the patient's inquiry and the subsequent pressure are ancillary to looking back through the patient's medical chart and taking notes in it—activities related to reviewing the patient's medical history. Even when she ultimately indicates that she will be ordering the test (in Extract 3), she does not acknowledge the patient's initiative in having brought up and having exerted pressure for the test. 
The patient's moves could possibly be interpreted as manipulative and the doctor's moves as inattentive or as unnecessarily resistive to the patient; alternatively, either party's behavior could be rationalized in some way. These interpretations, however, would prevent an understanding of what activities the patient and doctor are doing and how they are doing them, as well as the recognition that both parties face interactional dilemmas that stem from the structure of the medical interview where history taking, physical examination, and recommendations typically occur in sequential order (Byrne \& Long, 1976; see also Gill \& Maynard, in press; Robinson, 2003). Recommendations for diagnostic testing normally occur after the doctor has completed a thorough assessment of the patient (having taken the patient's history and having performed a physical exam). As shown in Extract $2 \mathrm{a}$, the doctor broke with this ordering when she proposed doing a test to check the patient's blood count after the patient suggested that a remedy for her fatigue would be to take additional iron. This exchange provided the patient with a niche to bring up an additional test, the SMAC, in a location where it would be otherwise more difficult to do so. However, the patient's inquiry about the SMAC test and eventual pressure for an offer could have put the doctor in the position of committing to a decision about ordering a test before having completed the history taking and examination, either of which could potentially turn up findings about the patient's various symptoms that could render the test necessary or unnecessary. The doctor addresses this dilemma by holding the patient in abeyance (offering the requested information but not offering the test or otherwise indicating her intentions to order it) until the patient capitulates, whereupon the doctor continues the history taking. After completing the history and physical exam, the doctor indicates that the SMAC test will be performed, as indicated by Extract 3 .

In this tug of war, then, the patient eventually gives way, but she does end up receiving the test. However, she did not actually request it, nor did the doctor grant it. Interactions of this type may be at the root of some of the oft-reported demand for medical interventions described at the beginning of this article. Although it is not possible to generalize from a single case analysis, it is conceivable that with some regularity, patients hint at their desires and apply subtle pressure on doctors to offer medical services and interventions such as diagnostic tests and that doctors may perceive these as demands. There is evidence that this occurs in pediatric visits. Studies have found that it is rare for parents to overtly request antibiotic treatment for their children in pediatric visits, but even when parents pres- 
ent their children's problems without explicitly requesting antibiotics, pediatricians often perceive that parents expect them (Stivers, 2002a, 2002b; Stivers et al., 2003). This means, following Stivers (2002a), that researchers who study patient demand need to take account of the various methods patients use to indicate their desires for medical services and interventions other than explicitly requesting them. However, researchers will miss the kinds of subtle dynamics explored here if they do not account for the possibility that an utterance can perform more than one action, that participants use utterance placement as an interpretive resource, and that activities emerge over extended sequences of talk (see Robinson, 2001; Schegloff, 1990). For example, recognizing that the patient's initial inquiry (Extract $2 \mathrm{~b}$, lines 10-11) is equivocal as a request for information and may call for the doctor to do more than provide information in response requires attention to its placement in the conversation and to the different ways that inquiries can be put to use (e.g., to solicit offers). It also requires attention to subsequent turns in the conversation, for they can provide evidence that former utterances were to be heard and responded to in a particular way. Understanding what the patient is doing when she praises a predecessor (Extract 2d) -in terms of its role in the conversation as an implicit criticism of the current doctor and as part of a larger process of exerting pressure for an offer-requires attention to the sequential context in which this action emerges.

This study also demonstrates that the aforementioned tug of war has a social dimension beyond the concurrent imperatives to partner with increasingly active and knowledgeable patients, meet their expectations, and control medical spending. The social organization of the medical interview itself has interactional ramifications for doctors and patients (Robinson, 2003; see Heritage \& Maynard, in press). It can produce interactional dilemmas for both parties, and these dilemmas have ramifications for patient participation and physician responsiveness. Is there a location in the medical interview where patients can appropriately make requests for medical interventions and services? How can physicians be responsive to patients' requests without making premature decisions that might later be difficult or impossible to retract? When the solutions to these dilemmas involve cautious and oblique strategies, the tug of war is no less real than in an outright argument. Therefore, any rational attempt to change features of these encounters entails not only a recognition of the subtle dynamics of doctor-patient encounters but must also be informed by an understanding of the orga- 
nization of the medical interview itself. If doctors are to be more responsive to patients and if patients are to participate more actively, then we must learn more about how the structure of the medical interview affects both parties' opportunities to engage in particular ways.

\section{NOTES}

1 "Patient-centered" care and "patient participation" have been conceptualized in various ways; for example, see Byrne and Long (1976); Coulter (1997); Frosch and Kaplan (1999); Institute of Medicine (2001); Kaplan, Greenfield, Gandek, Rogers, and Ware (1996); Makoul (2001); Mead and Bower (2000); Robinson (2003); Roter and Hall (2004); and Stewart (1984).

2 Mangione-Smith et al. (1999) who examined pediatric visits, assessed the relationship between parents' (rather than patients') expectations for antibiotics for their children and parental satisfaction.

3 For comprehensive descriptions of conversation analysis, see Heritage (1984), Hutchby and Wooffitt (1998), and ten Have (1999).

4 I express my appreciation to Doug Maynard for sharing these data.

5 Sacks (1971/1992b) characterized such speculative formulations as "musing aloud" (p. 405). This type of formulation has also been discussed by ten Have (1991) and Robinson (2003) in addition to Gill (1998) and Gill and Maynard (in press).

6 Patients' medical charts are typically organized chronologically, with notes from the most recent visit on top. The chart is fastened at the top. Thus, "paging back" involves flipping a page up, and this reveals notes about prior medical visits.

7 On third-party attributions in medical contexts, see also Bergmann (1992), Drew (1991), and Gill (1998).

8 There is also evidence that the patient is implicitly correcting the copresent doctor by invoking a different, possibly upgraded set of symptoms than "fatigue," the symptom the doctor cited in line 15 as a precondition for the test. Recall that earlier in the visit (in Extract 1), the patient had indicated that she was experiencing tenderness under her rib. In Extract 2c, line 17, the patient invokes a similar symptom, "soreness," but she also includes additional health conditions that she experienced when she was under her former doctor's care ("lumps er stuff"). By citing the anxiety she experienced about "soreness er lumps er stuff::" in the past, she may be indicating that what she is currently concerned about is the soreness under her rib rather than (or in addition to) the possibly more benign "fatigue" the doctor mentioned in line 15 . The doctor does orient to this as a correction; in line 28 , she portrays the test as a way to investigate "this" while gesturing under her rib, the location the patient had indicated was tender.. 
9 In contrast, preinvitations, preoffers, and preannouncements prefer go-ahead responses, which allow the speaker to then invite, offer, or deliver an announcement (Schegloff, 1995, pp. 86-89).

10 Maynard (1998) shows how, in the context of a bad news delivery, a speaker uses praise of a predecessor to covertly criticize a person with whom she is speaking. In a phone conversation with her son's Spanish teacher (Mrs. Stewart), a mother receives the bad news that her son is getting a D in 1st-year Spanish and should repeat the class. The mother covertly blames the current teacher by praising her predecessor, the son's former Spanish teacher (Mrs. Anderson):

[from Maynard, 1998, pp. 388-389]

1 Mother: Now I'm sitting her:e, and I'm listening, ta someone tell

2 me::, that they think that he ought to repea::t, it, in a

3 very stro::ng sort of $\uparrow$ wa:y. .hhh an I guess I'm r::eally

4

5 Stewart: Okay=

6 Mother: -An' I'm $\uparrow$ al $\downarrow_{\text {so concerned, because I:, I- a:n an' that }}$ has nothing ta ya know say: hh but you know he h::a:d a very good start with Missus Anderson.

Stewart: $\mathrm{Mm} \mathrm{hmm}=$

Mother: =A:n' I'm not ya know co:mmenting on the teaching? because I I have na- absolutely no idea .hhh but he was very happy with her, $\mathrm{h}$ [e liked ] her a lot,=

14 Mother: =an I was r:eally ve:ry very much hoping .hh that he would've had her this year. .hhh and that's not saying anything, you know, negative about you:. It was just that we had a very fi:ne experience, [with he]r=

$$
\begin{array}{lc}
\text { Stewart: } & \text { [Right. ] } \\
\text { Stewart: } & =\text { hhh We [ll ] } \\
\text { Mother: } & \text { [An'] I I hav:e to::, ya know I=m sitting in the }
\end{array}
$$

Although the mother does not openly criticize the current Spanish teacher, by praising the former teacher, she implicitly blames the current teacher for her son's performance. As Maynard (1998) explains, her denials (lines 10-11, 15-16) also demonstrate "an understanding that such praise and appreciation could be heard as saying something negative about [her son's] present teacher, Mrs. Stewart" (p. 390). Mrs. Stewart hears the praise of her predecessor as criticism of her teaching. In further talk, she reacts defensively, claiming that she has been using the same curriculum as the former teacher:

[from Maynard, 1998, pp. 388-389]

35 Mother: [An' I don't know you [r teaching (style)]

36 Stewart: [.hhhhhhhhhhhhhhhhhhh[Well:: ] I have been 
39 Mother:

40 Stewart:

41

42

43 teaching the same curriculum:, eghhm that (.) Julie has been tea [ching.] [.hhh] [for years: and I have] been= [Right.] $=$ [I un ] [derstand that. ] =supplementing .hhh tha::t with some work out of the

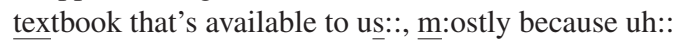
.hhh she has been teaching her curriculum fer years and it's kind of hard to step into someone else's curriculum.

Eventually, the mother announces, "He is going to sign up for the Spanish Two class," and Mrs. Stewart responds, “Okay that's fine.” Maynard (1998) argues that the mother's blaming of Mrs. Stewart works in the service of this alternative proposal.

11 Note how the patient delimits her praise of the former doctors with "as far as" (Extract $2 \mathrm{~d}$, line 34$)$. Earlier in the visit, she had criticized a former physician for being "much too non-verbal for me to deal with." "As far as" may be an oblique reference to that criticism in that it portrays her former doctors not in a global way as "good" but at least "good at explaining." She may be implying that the copresent doctor should at least be able to exhibit that behavior as well.

\section{REFERENCES}

Avorn, J., \& Solomon, D. (2000). Cultural and economic factors that (mis)shape antibiotic use: The nonpharmacologic basis of therapeutics. Annals of Internal Medicine, 133, $128-135$.

Berger, P. (1997). Paying physicians in advanced managed care markets. Physician Executive, 23, 25-27.

Bergmann, J. (1992). Veiled morality: Notes on discretion in psychiatry. In P. Drew \& J. Heritage (Eds.), Talk at work: interaction in institutional settings (pp. 137-162). Cambridge, England: Cambridge University Press.

Bradley, L., \& Zito, J. (1997). Direct to consumer prescription drug advertising. Medical Care, 35, 86-92.

Brody, D., Miller, S., Lerman, C., Smith, D., Lazaro, C., \& Blum, M. (1989). The relationship between patients' satisfaction with their physicians and perceptions about interventions they desired and received. Medical Care, 27, 1027-1035.

Butler, C.C., Rollnick, S., Pill, R., Maggs-Rapport, F., \& Stott, N. (1998). Understanding the culture of prescribing: Qualitative study of general practitioners' and patients' perceptions of antibiotics for sore throats. British Medical Journal, 317, 637-642.

Byrne, P., \& Long, B. (1976). Doctors talking to patients: A study of the verbal behaviours of general practitioners consulting in their surgeries. London: Her Majesty's Stationery Office.

Cegala, D., McClure, L., Marinelli, T., \& Post, D. (2000). The effects of communication skills training on patients' participation during medical interviews. Patient Education and Counseling, 41, 209-222.

Coulter, A. (1997). Partnerships with patients: The pros and cons of shared clinical decision-making. Journal of Health Services Research and Policy, 2, 112-121. 
Drew, P. (1991). Asymmetries of knowledge in conversational interactions. In I. Markova \& K. Foppa (Eds.), Asymmetries in dialogue (pp. 21-48). Hemel Hempstead, England: Harvester Wheatsheaf.

Drew, P., \& Holt, E. (1998). Figures of speech: Figurative expressions and the management of topic transition in conversation. Language in Society, 27, 495-522.

Eisenthal, S., Koopman, C., \& Lazare, A. (1983). Process analysis of two dimensions of the negotiated approach in relation to satisfaction in the initial interview. The Journal of Nervous and Mental Disease, 171, 49-54.

Froehlich, G., \& Welch, H. (1996). Meeting walk-in patients' expectations for testing: Effects on satisfaction. Journal of General Internal Medicine, 11, 470-474.

Frosch, D., \& Kaplan, R. (1999). Shared decision-making in clinical medicine: Past research and future directions. American Journal of Preventive Medicine, 17, 285-294.

Gill, V. (1998). Doing attributions in medical interaction: Patients' explanations for illness and doctors' responses. Social Psychology Quarterly, 61, 342-360.

Gill, V., Halkowski, T., \& Roberts, F. (2001). Accomplishing a request without making one: A single case analysis of a primary care visit. Text, 21, 55-81.

Gill, V., \& Maynard, D. (in press). Explaining illness: Patients' proposals and physicians' responses. In J. Heritage \& D. Maynard (Eds.), Communication in medical care: Interaction between primary care physicians and patients. Cambridge, England: Cambridge University Press.

Greenfield, S., Kaplan, S., \& Ware, J. (1985). Expanding patient involvement in care: Effects on patient outcomes. Annals of Internal Medicine, 102, 520-528.

Greenfield, S., Kaplan, S., Ware, J., Yano, E., \& Frank, H. (1988). Patients' participation in medical care: Effects on blood sugar control and quality of life in diabetes. Journal of General Internal Medicine, 3, 448-457.

Haakana, M. (2001). Laughter as a patient's resource: Dealing with delicate aspects of medical interaction. Text, 21, 187-219.

Halkowski, T. (in press). Realizing the illness: Patients' reports of symptom discovery in primary care visits. In J. Heritage \& D. Maynard (Eds.), Communication in medical care: Interaction between primary care physicians and patients. Cambridge, England: Cambridge University Press.

Heritage, J. (1984). Garfinkel and ethnomethodology. Cambridge, England: Polity Press.

Heritage, J., Boyd, E., \& Kleinman, L. (2001). Subverting criteria: The role of precedent in decisions to finance surgery. Sociology of Health and Illness, 23, 701-728.

Heritage, J., \& Maynard, D. (Eds.). (in press). Medical encounters: Communication in medical care: Interaction between primary care physicians and patients. Cambridge, England: Cambridge University Press.

Heritage, J., \& Sorjonen, M. (1994). Constituting and maintaining activities across sequences: And-prefacing as a feature of question design. Language in Society, 23, 1-29.

Holman, H., \& Lorig, K. (2000). Patients as partners in managing chronic disease. Partnership is a prerequisite for effective and efficient health care. British Medical Journal, 320, 526-527.

Hutchby, I., \& Wooffitt, R. (1998). Conversation analysis: Principles, practices, and applications. Cambridge, England: Polity Press.

Institute of Medicine, Committee on Health Care in America. (2001). Crossing the quality chasm: A new health system for the 21 st century. Washington, DC: National Academy Press. 
Joos, S., Hickam, D., \& Borders, L. (1993). Patients' desires and satisfaction in general medicine clinics. Public Health Reports, 198, 751-759.

Kaplan, S., Greenfield, S., Gandek, B., Rogers, W., \& Ware, J. (1996). Characteristics of physicians with participatory decision-making styles. Annals of Internal Medicine, 124, 497-504.

Kaplan, S., Greenfield, S., \& Ware, J. (1989). Assessing the effects of physician patient interaction on the outcomes of chronic disease. Medical Care, 27, 110-127.

Kowalczyk, L. (2002, December 17). Blue Cross to give doctors care-, cost-based bonuses. The Boston Globe, p. A1.

Kravitz, R., Bell, R., Azari, R., Kelly-Reif, S., Krupat, E., \& Thom, D. (2003). Direct observation of requests for clinical services in office practice. What do patients want and do they get it? Archives of Internal Medicine, 163, 1673-1681.

Kravitz, R., Bell, R., Azari, R., Krupat, E., Kelly-Reif, S., \& Thom, D. (2002). Request fulfillment in office practice. Medical Care, 40, 38-51.

Kravitz, R., Bell, R., \& Franz, C. (1999). A taxonomy of requests by patients (TORP): A new system for understanding clinical negotiation in office practice. The Journal of Family Practice, 48, 872-878.

Kravitz, R., Callahan, E., Azari, R., Antonius, D., \& Lewis, C. (1997). Assessing patients' expectations in ambulatory medical practice: Does the measurement approach make a difference? Journal of General Internal Medicine, 12, 67-72.

Kravitz, R., Cope, D., Bhrany, V., \& Leake, B. (1994). Internal medicine patients' expectations for care during office visits. Journal of General Internal Medicine, 9, 75-81.

Lazare, A., Eisenthal, S., \& Wasserman, L. (1975). The customer approach to patienthood: Attending to patient requests in a walk-in clinic. Archives of General Psychiatry, 32, 553-558.

Lerner, G. (1996). Finding "face" in the preference structures of talk-in-interaction. Social Psychology Quarterly, 59, 303-321.

Like, R., \& Zyzanski, S. (1987). Patient satisfaction with the clinical encounter: Social psychological determinants. Social Science and Medicine, 24, 351-357.

Lipsky, M., \& Taylor, C. (1997). The opinions and experiences of family physicians regarding direct-to-consumer advertising. The Journal of Family Practice, 45, 495-499.

Macfarlane, J., Holmes, W., Macfarlane, R., \& Britten, N. (1997). Influence of patients' expectations on antibiotic management of acute lower respiratory tract illness in general practice: Questionnaire study. British Medical Journal, 315, 1211-1214.

Makoul, G. (2001). Essential elements of communication in medical encounters: The Kalamazoo consensus statement. Academic Medicine, 76, 390-393.

Mangione-Smith, R., McGlynn, E., Elliott, M., Krogstad, P., \& Brook, R. (1999). The relationship between perceived parental expectations and pediatrician antimicrobial prescribing behavior. Pediatrics, 103, 711-718.

Maynard, D. (1998). Praising versus blaming the messenger: Moral issues in deliveries of good and bad news. Research on Language and Social Interaction, 31, 359-395.

Mead, N., \& Bower, P. (2000). Patient-centredness: A conceptual framework and review of the empirical literature. Social Science and Medicine, 51, 1087-1110.

Peyrot, M., Alperstein, N., Van Doren, D., \& Poli, L. (1998, Summer). Direct-to-consumer ads can influence behavior: Advertising increases consumer knowledge and prescription drug requests. Marketing Health Services, 27-32. 
Pomerantz, A. (1984a). Agreeing and disagreeing with assessments: Some features of preferred/dispreferred turn shapes. In J. Atkinson \& J. Heritage (Eds.), Structures of social action: Studies in conversation analysis (pp. 57-101). Cambridge, England: Cambridge University Press.

Pomerantz, A. (1984b). Giving a source or basis: The practice in conversation of telling "How I Know." Journal of Pragmatics, 8, 607-625.

Pomerantz, A. (1984c). Pursuing a response. In J. Atkinson \& J. Heritage (Eds.), Structures of social action: Studies in conversation analysis (pp. 152-163). Cambridge, England: Cambridge University Press.

Raymond, G. (2003). Grammar and social organization: Yes/no interrogatives and the structure of responding. American Sociological Review, 68, 939-967.

Robinson, J. (2001). Asymmetry in action: Sequential resources in the negotiation of a prescription request. Text, 21, 19-54.

Robinson, J. (2003). An interactional structure of medical activities during acute visits and its implications for patients' participation. Health Communication, 15, 27-59.

Roter, D., \& Hall, J. (2004). Physician gender and patient-centered communication: A critical review of empirical research. Annual Review of Public Health, 25, 497-519.

Sacks, H. (1992a). Lectures on conversation (G. Jefferson, Ed., Vol. 1, pp. 685-692). Oxford, England: Blackwell.(Original work published 1967)

Sacks, H. (1992b). Lectures on conversation. (G. Jefferson, Ed., Vol. 2, pp. 402-409). Oxford, England: Blackwell. (Original work published 1971)

Schegloff, E. (1987). Analyzing single episodes of interaction: An exercise in conversation analysis. Social Psychology Quarterly, 50, 101-114.

Schegloff, E. (1988). Presequences and indirection: Applying speech act theory to ordinary conversation. Journal of Pragmatics, 12, 55-62.

Schegloff, E. (1990). On the organization of sequences as a source of 'coherence' in talk-in-interaction. In B. Dorval (Ed.), Conversational organization and its development (pp. 51-77). Norwood, NJ: Ablex.

Schegloff, E. (1995). Sequence organization. Unpublished manuscript, Department of Sociology, University of California, Los Angeles.

Schegloff, E., \& Sacks, H. (1973). Opening up closings. Semiotica, 7, 289-327.

Scott, J., Cohen, D., DiCicco-Bloom, B., Orzano, A., Jaen, C., \& Crabtree, B. (2001). Antibiotic use in acute respiratory infections and the ways patients pressure physicians for a prescription. The Journal of Family Practice, 50, 853-858.

Sleath, B., Svarstad, B., \& Roter, D. (1997). Physician vs. patient initiation of psychotropic prescribing in primary care settings: A content analysis of audiotapes. Social Science and Medicine, 44, 541-548.

Stewart, M. (1984). What is a successful doctor-patient interview? A study of interactions and outcomes. Social Science and Medicine, 19, 167-175.

Stivers, T. (2002a). Participating in decisions about treatment: Overt parent pressure for antibiotic medication in pediatric encounters. Social Science and Medicine, 54, 1111-1130.

Stivers, T. (2002b). Presenting the problem in pediatric encounters: "Symptoms only" vs. "candidate diagnosis" presentations. Health Communication, 14, 299-338.

Stivers, T., Mangione-Smith, R., Elliott, M., McDonald, L., Heritage, J. (2003). Why do physicians think parents expect antibiotics? What parents report vs. what physicians believe. The Journal of Family Practice, 52, 140-148. 
ten Have, P. (1991). Talk and institution: A reconsideration of the "asymmetry" of doctor-patient interaction. In D. Boden \& D. Zimmerman (Eds.), Talk and social structure: Studies in ethnomethodology and conversation analysis (pp. 138-163). Berkeley: University of California Press.

ten Have, P. (1999). Doing conversation analysis: A practical guide. London: Sage.

Uhlmann, R., Inui, T., Pecoraro, R., \& Carter, W. (1988). Relationship of patient request fulfillment to compliance, glycemic control, and other health care outcomes in insulin-dependent diabetes. Journal of General Internal Medicine, 3, 458-463.

Weijer, C., Singer, P., Dickens, B., \& Workman, S. (1998). Bioethics for clinicians: Dealing with demands for inappropriate treatment. Canadian Medical Association Journal, 159, 817-821. 